\title{
El Arte Narrativo en Sin Rumbo
}

Una de las novelas hispanoamericanas del siglo XIX más notables desde el punto de vista de la técnica y del arte narrativo es Sin rumbo (1885) del argentino Eugenio Cambaceres. Por muchos años la crítica miró esta obra con ojos miopes, aunque hubo excepciones desde el principio, como la de Garcìa Mérou. ${ }^{1}$ Esa crìtica, fácilmente escandalizable, la juzgó sólo como ejemplo de novela naturalista, deleitándose en mostrar lo más sórdido de la novela y enfatizando los defectos heredados de la escuela zoliana sin detenerse a analizar los grandes aciertos del autor en la obra que nos ocupa. En años recientes la crítica le ha dedicado algunos estudios más serios. Hay que destacar al respecto la perspicaz introducción a la edición de Anaya hecha por Ana Marìa Bastos, ${ }^{2}$ quien con acierto sitúa a Sin rumbo entre las novelas clásicas de Hispanoamérica.

La vigencia de esta novela es indiscutible; hoy se la lee con verdadero interés, sobretodo por el dinamismo que emana de sus páginas. La técnica que utiliza su autor denota grandes avances sobre las novelas anteriores hispanoamericanas. De ahí que en la actualidad, el acierto y la originalidad de Sin rumbo no parezcan estar tanto en el tema naturalista determinista tan en boga a fines del siglo pasado, ni tampoco en la filosofía schopenhaueriana que exuda, sino en la ceñida narración, casi siempre expresada en escuetas líneas. Al aspecto del arte narrativo de Sin rumbo queremos enfocar este trabajo, y en forma especial, a la compleja interrelación y compenetración de contenido y forma, desalojando cuestiones marginales, como el naturalismo o la argentinidad de la obra. 
Sin rumbo es una novela breve, dividida en capítulos muy breves, algunos de media página, y el más largo, de ocho páginas. La novela se compone de dos partes principales. La primera tiene 32 capítulos, que se pueden dividir espacialmente de la siguiente manera: capítulos 1 a 13 ubicados en el campo en la estancia del protagonista (13 capítulos); capítulos 14 a 26 en la ciudad de Buenos Aires (13 capítulos); se cierra la primera parte del libro con los capítulos 27 a 32, de vuelta en el campo ( 6 capítulos, la mitad, o casi la mitad de 13). La segunda parte de la novela, mucho más breve que la primera, consta de los capítulos 33 a 45, también en la estancia (otra vez 13 capítulos). Estas divisiones $(13,13,6,13)$ no pueden ser totalmente casuales, sino que obedecen a una rigurosa simetrïa formal por parte del autor. Cuando empezamos a examinar más detalladamente la estructura interior de la obra, nos damos cuenta de que la novela sigue rindiendo otros interesantes paralelismos y simetrías que cuadran perfectamente con la forma exterior en su acertado sentido de bellas proporciones.

Uno de los paralelismos más destacables es el de las escenas que abren y cierran el relato. La escena inicial, en la que los hombres están esquilando las ovejas en el galpón de la estancia de Andrés, a primera vista puede aparecer nada más que como una escena costumbrista, pero es en realidad una anticipación de la trágica escena final de la novela. En la primera página, Cambaceres enfoca directamente en las ovejas, "brutalmente maneadas de las patas, echadas de costado unas junto a otras, las caras vueltas hacia el lado del corral,"3 con los ojos entrecerrados de dolor, jadeando. En seguida enfoca en las tijeras, que van hundiéndose en los vellones, pellizcando el cuero. "Las carnes, cruelmente cortajeadas, se mostraban en heridas anchas, desangrando." (26) Y en la escena final vemos al protagonista abriéndose su barriga en cruz, "de abajo arriba y de un lado a otro, toda" (164). Asî el relato queda enmarcado entre estas dos escenas, la inicial de las ovejas y el dramático suicidio final. ${ }^{4}$

\section{III}

Acción, violencia y tensión marcan el paso de Sin rumbo. El dinamismo de la novela se debe en gran parte al lenguaje lleno de imágenes de movimiento, sobre todo los verbos, que llenan sus páginas y que contribuyen a una textura retórica de alta tensión y dramatismo. Al examinar la estructura de Sin rumbo, se destaca primero 
una trama tejida con imágenes de movimiento de la que emerge un diseño de motivos reiterados: la violencia y el teatro. Desde la escena inicial de la esquila hasta la trágica escena final, todo se esfuerza por ponerse en movimiento. Se describe variadamente como camino, dirección, rumbo (desde el título), viaje, etc, y se nota sobre todo en las acciones de Andrés. $Y$ esto a pesar de cierta insistencia en el no-movimiento, en la abulia de Andrés de algunos momentos en el "sin rumbo" de su vida, cuando se sumerge en estados de depresión. 5

Los vocablos naturalistas y científicos no predominan en la configuración de Sin rumbo, sino que llaman más bien la atención cuando aparecen de vez en cuando. ${ }^{6}$ Lo que sỉ se destaca en cuanto al lenguaje es su expresiva vitalidad. El paso acelerado de la novela se debe en gran parte al lenguaje a menudo violento, de estilo casi elíptico, donde se destacan los verbos. Esta retórica refuerza y armoniza con el tema conflictivo de la novela y refleja también el estado de ánimo nervioso y mudable del protagonista.

La primera escena de la novela, a que ya me he referido, representa muy bien este movimiento y da la tónica a lo que sigue. Citemos un poco: ". . . las tijeras. . .cortaban, corrian, se hundian entre el vellón como bichos asustados buscando un escondite..." (26). A continuación presenciamos la violenta escena entre el chino y el patrón: el peón le insulta y Andrés lo bofetea y lo despide. En el capítulo $\mathrm{V}$ vemos a Andrés sumido en un gran pesimismo, pero en seguida reacciona:

De pronto, un deseo violento de salir, de andar, una fiebre, un furor de movimiento lo asaltaba.

Ensillaba él mismo su caballo, y contra el viento, el sombrero en la nuca, lagrimeándole los ojos, silbándole los oỉdos, galopaba, corría, devoraba locamente las distancias.

O la pasión de la caza llegaba a absorberlo por completo y se levantaba entonces al alba y en su afán de matar y de hacer daño, ganaba al campo. (39-40).

Este último motivo de la caza, que se presta naturalmente a imágenes de movimiento y violencia, está concretizado en esta misma escena en el gato de Andrés, perseguido por el perro del capataz; a su vez, el gato, tomando refugio en un árbol donde hay un nido de pájaros, parece acosar a las aves, y la hembra:

entonces, alarmada, creyendo en una agresión, encrespó furiosa las plumas; gritaba, se agitaba, golpeaba desespera- 
damente el pico contra el gajo.

El gato, por su parte, haciendo caso omiso de aquella vana hojarasca y todo estremecido aún por la eminencia del peligro, clavaba las uñas en el árbol y los ojos en el suelo donde, lamiéndose el hocico y sacudiendo la cola con un movimiento nervioso de culebra, su terrible adversario lo acechaba. (41)

Otra descripción que es puro movimiento con efectos auditivos además de lo gráfico visual muy bien captado que es típico de esta novela se encuentra en el capítulo VII, dedicado a describir una fiesta campestre:

En las pulperǐas, los borrachos, los "mamaos" quemaban gruesas de cohetes.

Los muchachos, en ronda, agarrados de las manos, saltaban gritando.

Los caballos atados a los postes de las veredas, asustados, se sentaban, reventaban los cabestros, las riendas.

De vez en cuando, un carricoche pasaba sonando con un ruido de matraca. Lo envolvỉa una nube de polvo. (42)

Multiplicar la enumeración de tales citas serỉa fácil pero ocioso; sólo quisiera cerrarla mencionando las palabras breves y desesperadas de Andrés cuando se enferma gravemente su hija de difteria y manda a buscar el médico: "Lleva si es necesario a toda su gente, mate la caballada... Quiero que corra, que vuele, que vaya y vuelva a rajacincha..." (148-149), palabras que representan muy bien el movimiento, la violencia, y la dramaticidad de la novela.

El motivo reiterado del teatro se encuentra por toda la segunda división de la primera parte. En los capítulos dedicados a los meses que Andrés pasa en Buenos Aires y al amorio tempestuoso que tiene con Marietta Amorini, la diva de la ópera, el teatro es la vida, las apariencias y la realidad de funden en una, el mundo novelesco se teatraliza. El narrador dice, comentando la vida placentera de Andrés en Buenos Aires: "buscaba un refugio... en el juego, en los teatros, en los amores fáciles de entretelones. . donde la farsa vivida no es otra cosa que una repetición grosera de la farsa representada." (60) La palabra farsa, reiterada varias veces en el texto, ayuda a crear esta atmósfera de representación y a dar cierto tono burlesco a esta parte de la novela.

La escena más teatral de la novela es la del capitulo XX en la que la Amorini propone a su amante Andrés que hagan el amor en el 
palco de éste en el teatro Colón, añadiendo: “ ¡Qué buena farsa para los otros! ¡Lástima, de veras, que no está el teatro lleno!” (86) A pesar de las protestas de Andrés, se realiza el capricho de la diva en una escena que es a su vez de farsa: el marido de la adúltera llama con alboroto a la puerta del palco, y la Amorini, confundida, huye por la reja.

El estilo staccato y nervioso presta fuerza al conjunto dramático de la novela. Hasta se puede hallar en sus páginas frases yuxtapuestas que funcionan para la escenificación de una manera semejante a las acotaciones en el texto de un drama:

A corta distancia estaba el puesto: dos piezas blanqueadas, de pared de barro y techo de paja.

A la izquierda, en ángulo recto, una ramada servia de cocina.

A la derecha, un cuadro, cercado de cañas: el jardín.

En frente, entre altos de viznaga, un pozo con brocal de adobe y tres palos de acacio, en horca, sujetando la roldana y la huasca del balde.

Más lejos, protegido por la sombra de dos sauces, el palenque.

Bajo el alero del rancho, colgando de la última lata del techo, unas bolas de potro se veľan. (33-34)

La primera escena en la ciudad, que contrasta violentamente con la primitividad y sencillez del campo y el personaje rústico de Donata, toma lugar en el teatro Colón donde se está haciendo un ensayo general de Aida. Bruscamente, Cambaceres mete a su protagonista en ese mundo de teatro, de farsa, de artificiosa realidad, y se demora más de lo común en presentárnoslo, llegando a ser este capítulo 14 de ocho páginas el más extenso de la novela. Pero será necesario, no sólo para la introducción del mundo urbano y teatral, sino para preparar el terreno al amorío que pronto se desarrollará con la Amorini y para introducirnos al grupo de personajes secundarios del teatro que rodean a la diva.

Cambaceres, a diferencia de la mayoría de los novelistas hispanoamericanos que le precedieron y de muchos contemporáneos suyos, no se dirige omniscientemente al lector con apartes que explican la acción, la motivación de personajes, etc. Sin embargo, nos deja saber mediante una cuidadosa selección de palabras sus prejuicios o reacciones a lo que ocurre en su novela por algunas indicaciones del narrador. Por ejemplo, cuando el empleado de la ópera 
deja pasar a Andrés, habiendo dicho recién a la muchedumbre ansiosa de entrar en el teatro que tiene órdenes para que no entre nadie, encontramos lo siguiente: "Un coro de destemplados protestas y de insultos acogió la odiosa excepción del empleado." (61) La frase tendrá casi el mismo significado, pero no la misma fuerza sin el adjetivo odiosa, y el autor no puede resistir la tentación de incluirlo.

Otro ejemplo más sugestivo se halla en el episodio final de la novela cuando presenciamos brevemente el incendio del galpón (volvemos al galpón lleno de ovejas del episodio inicial del libro). Dice el narrador: "Poco a poco el edificio entero se abrasaba, era una enorme hoguera, y a su luz, allá, detrás del monte, por las abras de los caminos, habría podido alcanzarse a distinguir un bulto, como la sombra de un hombre que se venga y huye." (163) Empleando el verbo vengar, el narrador nos insinúa lacónica y soslayadamente, al chino Contreras, que aparece contadas veces siempre en una acción alevosa y violenta y que aquǐ en el mismo lugar del galpón donde fue humillado por el patrón al comienzo de la novela, se desquita de él al final. 7

El lector de Sin rumbo estará bastante preparado para el suicidio final de la novela, puesto que habrá visto a Andrés sumido varias veces en estados de desesperanza. El suicidio es, pues, acto apropiado para resolver problemas para él insolubles, y para poner término a "la noche negra y helada de su vida." (85) Desde el tittulo tan acertado y significativo, Cambaceres nos da a entender que algo está mal. La expresión "sin rumbo" se encuentra dos veces en el texto $(85,101)$, y otra expresión parecida, "bola sin manija" (104), aparece en la carta de despedida que Andrés le pone a Marietta, describiendo a ésta.

Mientras más nos adentramos en la lectura de la novela, vamos encontrando varias citas directas, además de las insinuaciones del tremendo tedio de Andrés, que confirman la idea del suicidio: rumbo. . .

Desalentado, rendido, postrado andaba al azar; sin

Pero, entonces, ¿por qué andar, por qué vivir?

Y la idea del suicidio, como una puerta que se abre de pronto entre tinieblas, atrayente, tentadora, por primera vez cruzó su mente enferma.

Matarse. . .

Sí, era una solución, una salida, un medio seguro y fácil de acabar. (85) 
Después, refiriéndose a la relación que tiene Andrés con la cantante Amorini, dice el narrador:

Habia momentos en que tentaciones brutales lo acometỉan: estrujarla, estropearla, insultarla, matarla y matarse él. . .

¿Qué ganaba con vivir, para qué servǐa? . . - -llegaba a exclamar acariciando más y más la idea de acabar por pegarse un tiro. (98)

Finalmente, en uno de los muy contados capitulos discursivos, el XXXIV, de la segunda parte, que contrasta con la dinámica general del texto, Andrés piensa en la triste condición de la mujer, y específicamente en sus temores por el porvenir de su hija Andrea:

Maldecia en esas horas de ofuscación y de extravio, renegaba de su suerte que lo había hecho padre.

Por él, obligado ahora a vivir en obsequio de su hija, restado a la existencia por ese nuevo vínculo de hierro, sin ni siquiera ser dueño de su bulto, libre de acabar por agujerearse el cráneo. . . (139-140)

Aquỉ la alusión a pegarse un tiro subraya de manera naturalista los efectos clínicos en la vǐctima.

Este uso reiterado de la premonición como recurso que anticipa el trágico fin del libro tiene el doble objeto de provocar un efecto de tensión y de preparar al lector para el suicidio final. Lo que sǐ sorprende al lector es que Andrés se suicide, abriéndose la barriga en cruz, con los consecuentes chorros de sangre y expulsión de tripas. Esto quizá satisfaga a los adeptos al naturalismo o a los que deseen atribuirle a la cruz una simbologïa cristiana. Cambaceres cumple asỉ con los preceptos de fatalidad de la escuela naturalista. Pero esta escena espantosamente brutal "sobre el telón de fondo del incendio está como acallada por la rapidez del desenlace: una vez más, hay que admirar la parquedad narrativa alcanzada por Cambaceres y la fuerza contundente de su lenguaje." 8

\section{IV}

Se ha dicho que los personajes de una novela son como un paisaje muy conocido, que de vez en cuando nos sorprenden cuando un efecto de luz o de sombra los altera o los vislumbramos desde una nueva perspectiva. Sus cualidades y defectos fundamentales no cambian; lo que cambia es nuestra conciencia de ellas. ${ }^{9}$ Los personajes de 
Sin rumbo, como los de tantas otras novelas hispanoamericanas del siglo XIX, poseen esta caracterǐstica de obedecer a un comportamiento inmutable. La excepción será Andrés, quien parece sufrir un cambio grande en la segunda parte del libro. Del personaje esencialmente egoissta y hedonista cambia hasta ser un padre abnegado. Diríamos entonces que la esencia de Andrés es la pasión obsesiva en uno u otro extremo de la gama de comportamientos que va del egoìsmo al amor paterno.

En la primera parte de la novela Andrés carece de motivación en su vida, pero en la segunda parte el abismo espiritual en que estaba sumido cambia por un tiempo. Su hija Andrea ha llegado a ser su razón de vivir. Eso le enseña a amar a otros y a buscar lo bueno en los demás: se siente "purificado en presencia de la niña, capaz de todas las virtudes, accesible a la bondad, inclinado a la indulgencia." (140) Esta situación, aunque poco duradera, sirve de contraste para la falta de sentido en la vida del protagonista predominante en la primera parte del libro.

Los primeros trece capitulos se desarrollan en el campo a fines de la primavera; cuando Andrés vuelve a su estancia es de nuevo primavera. Esta primavera es también espiritual, porque el nacimiento de la hija lo ha renovado. Al comenzar la segunda parte de la novela, luego de un lapso de dos años, otra vez es primavera. Andrés es optimista, lleno de planes para el futuro de su hija, pero esta felicidad se troncha brutalmente poco después con el fallecimiento de Andrés.

En Sin rumbo casi no hay capítulo ni escena donde el enfoque no recaiga sobre Andrés. Una excepción es el XXII, donde el amigo oficioso de Andrés interviene por él, va a ver a Gorrini con la historia fabricada de lo que pasó en el palco, pero aún aquǐ el asunto tiene que ver con el protagonista. A Andrés le vemos sucesivamente enojado, violento, apasionado, nervioso, cínico, escéptico, empalagado, y hastiado de la vida urbana sobretodo. Después, contento con su hija, mimándola, tierno, abnegado, frenético con su enfermedad, a veces muy activo, otras, fatigado y abúlico, al final desesperado, y finalmente un suicida. Su naturaleza impulsiva y violenta lo destruye a él y también a otros personajes que tienen la desventura de relacionarse con él, como la pobre Donata y su viejo padre ingenuo, Ño Refugio.

Cambaceres muestra la historia a través de los ojos de Andrés, o de su punto de vista, aunque no esté contada por él como narrador. El escritor, en su empleo de una vista que abarca la intimidad de Andrés, logra una técnica exitosa, instigando muchas veces una co- 
rrespondencia paralela emocional entre el protagonista con sus fallas evidentes y el lector. Presentado Andrés únicamente de una manera exterior, nos pudiera haber parecido antipático o simplemente patético.

Otro acierto artístico de Cambaceres es la pintura de caracteres en pocas palabras. Casi todos los personajes menores están determinados por su ambiente y la época en que se mueven, y además por las características de su temperamento. Algunos también se caracterizan onomásticamente, revelando por el nombre o el apodo su comportamiento. Este recurso tal vez no sea tan notable en Cambaceres como en algunos otros novelistas hispanoamericanos, 10 pero en Sin rumbo se puede señalar un ejemplo obvio como el de la Amorini (amor, amorio). Otros ejemplos quizá menos evidentes de la caracterización onomástica son Donata (donar, dar), cuyo nombre señalará esta cualidad, el chino Contreras (que sugiere contra), figura antagónica al patrón, y Gorrini, a quien le ponen el gorro.

$\mathrm{La}$ Amorini, además de la caracterización implicada en su nombre, se destaca, junto con su marido, como personaje tipo o hasta caricaturesco. Ella es la cantante egoǐsta, melodramática, voluptuosa, la prima donna caprichosa y voluble, y -cuando Andrés y nosotros llegamos a conocerla un poco mejor- sobre todo vulgar. Muy pronto Andrés se cansa de ella; su admiración se vuelve aversión, y la linda mujer se vuelve grotesca en la visión caricaturesca de Andrés. El narrador la describe en un pasaje naturalista, enfocándose clïnicamente en sus defectos, con una lupa cruel:

Repetía las cosas al revés, como lora, no le daba, no caìa, no entendía, jera decididamente una bruta!

$Y$ hasta era fea: tenía los ojos metidos en la nuca, la punta de la nariz medio de lado, las orejas mal hechas, la boca grande, los brazos flacos y las piernas peludas, como piernas de hombre. . .

En la mesa olía a comida y usaba escarbadientes. (97)

Todo el grupo de personajes secundarios del teatro, que incluye la Amorini, su marido Gorrini, la Machi -otra cantante que rivaliza con la prima donna-, está en general tratado con más detenimiento que el grupo de personajes campestres. 11 Cambaceres los mira y describe con ojos burlones, a diferencia de su tratamiento generalmente simpático de los personajes rústicos o gauchescos, como Donata, No Refugio, el mayordomo Villalba. 
El más absurdo de los personajes teatrales es el cornudo Gorrini. $\mathrm{Al}$ presentarlo por primera vez, el autor deja caer una pequeña clave, como de paso, que hace ver al lector, en forma obvia, lo que va a ocurrir entre la Amorini y Andrés, aunque las palabras suscitadoras de la señora al protagonista ya nos habrá insinuado la idea del adulterio un poco antes. Describe a Gorrini en los siguientes términos: "Era joven, blanco, fresco, bonito, de bigotito negro retorcido; fumaba cavours, usaba cuellos escotados y cuernos de coral en la cadena." (65) El juego de palabras con cuernos, aquỉ anticipado por parte del narrador, hace cómplice al lector, y lejos de destruir la tensión y el suspenso, los aumenta.

Este patético hombre está caracterizado en otro momento, en la escena ya aludida del palco. Gorrini golpea estridentemente en la puerta del palco de Andrés, buscando a su mujer. Comenta el narrador: "Irritado a pesar suyo, sin querer estarlo, sin darse cuenta de que lo estaba, mareado, entusiasmado como se entusiasman los cobardes, al eco de su propia voz, sacudía la puerta con violencia." (90) Más tarde, cuando va el amigo intercesor de Andrés a explicarle a Gorrini lo que pasó en el palco, inventando una historia mentirosa pero posible para disculpar a la Amorini, la reacción de Gorrini es interesante y cuadra bien con su carácter. Le agradece a su interlocutor por su intención de salvar las apariencias, que en el fondo son lo único que le importan a Gorrini, pero en seguida reacciona amargamente contra su mujer, porque le habǐa "deshonrado a él, un noble, un conde, un hijo de ilustre raza" (95), sin lamentar la deshonra a él como hombre. Finalmente, Gorrini está caracterizado por Andrés en la carta de despedida que le pone a la cantante: "te conviene un hombre. Aunque sea un hombre de paja como tu marido." (104)

\section{$\mathrm{V}$}

Además de la visión algo deformadora de la vida teatral que vislumbramos en la novela, hay un episodio a fines de la primera parte donde estamos plenamente en el terreno de lo grotesco. Se trata del capítulo XXVIII, enteramente dedicado a reproducir las monstruosas imágenes del sueño de Andrés cuando huye de la ciudad rumbo a su estancia, pensando en el hijo que le va a nacer. Como pasa comúnmente en los sueños, la imagen principal va metamorfoseándose, en esta instancia, de hijo grande y poderoso, en enano, en chancho, en escuerzo, quimeras pesadillescas que cuadran bien con el ambiente onírico de fantasía, y tipifican la deformación grotesca: 
Pero incoherente luego, informe, como se borran las imágenes en un teatro de sombras chinescas, la luminosa visión se disipaba envuelta en las caprichosas redes de la fantasía, y de la vaga y poca nebulosa provocada por el sueño en el cerebro de Andrés, repentinamente un monstruo se desprendía.

Un monstruo horrible, un enano deforme, de piernas flacas y arqueadas, de cabeza desmedida, de frente idiota.

Los músculos tirantes, inyectadas las venas del pescuezo, como a extremo de reventar bajo la piel amorotada $y$ fofa, en el enorme esfuerzo, un sonido inarticulado atinaba sólo a salir de su garganta, estridente, agrio, semejante al grito avieso de la lechuza. (108)

A continuación el narrador nos dibuja la metamorfosis del enano en cerdo con unas imágenes gráficas, y otra vez, de rápido movimiento, del desorden que causa este animal. Estas imágenes sugieren claramente una escena de orgía sexual, con exuberantes notas grotescas y caricaturescas. La figura predominante del chancho metiéndose entre las piernas de hombres y mujeres es seguida por otras deformaciones animalescas y monstruosas:

El monstruo echaba a correr, se convertía en un chancho, retozaba, se perdia en el tumulto, entre las piernas de los hombres, bajo las polleras de las mujeres, y hombres y mujeres derribados por él, caían unos sobre otros, en montón.

Luego, más allá, en un claro, apareció de nuevo, saltaba, era un escuerzo ahora, se hinchaba, se agrandaba; los otros se echaban sobre él, se empeñaban en aplastarlo a tacazos.

Pero Andrés desesperado, lo defendía a empujones, a golpes ensanchaba al claro, contenia a la muchedumbre, se arrojaba jadeante encima de él, le hacía un escudo con su cuerpo, y como amparan las comadrejas acosadas a sus crías, se lo echaba al seno y disparaba. . .

La impresión de aquella piel, pustulosa y fría de reptil en contacto con su piel, todo entero lo erizaba, la rechifla sangrienta, el grito atroz:

" ¡Su hijo, su hijo, es su hijo!", como el cintarazo de una verga zurriaba en sus oídos. (108-109) 
He citado extensamente, porque de otra manera es imposible captar íntegramente el sabor y la fuerza del original. Esta descripción del sueño de Andrés es la más grotesca de la novela, pero se pueden señalar otras, en especial, unas netamente naturalistas, que amenazan caer en lo grotesco, como por ejemplo, el episodio final del suicidio. La nota grotesca, aunque no sea la más destacada de Sin rumbo, está sugerida varias veces y ayuda a crear la atmósfera cargada de tensión y angustia en que vive Andrés. Las imágenes del episodio onírico citado arriba insinúan ya, aunque en forma embrionaria, el carácter surrealista magistral de muchas imágenes grotescas en la novela hispanoamericana del siglo XX, como por ejemplo en El Señor Presidente de Miguel Angel Asturias.

\section{VI}

\section{CONCLUSION}

Con esta relectura de Sin rumbo, enfocando nuestra atención en los aspectos más notables de su arte narrativo, nos damos cuenta cabal de que debajo de la superficie naturalista, con sus alusiones directas al pesimismo schopenhaueriano, hay una gran vitalidad que hace a esta novela vigente casi cien años después de su primera aparición en 1885. Cambaceres consigue esta vitalidad mediante su arte de narrar y su poderoso sentido dramático. En este apretado volumen de escuetas líneas, a diferencia de la mayorĭa de las novelas hispanoamericanas del siglo pasado que llegaron a llenar dos o tres veces la extensión de ésta, se nota desde el comienzo el dinamismo y la intensidad con que se despliega y se desarrolla la novela hasta su fin.

El autor argentino logra sus efectos imaginativos y su interés dramático a través de la maestría técnica y formal, con cierta unidad en su diseño y una justa proporción y simetrĭa en sus partes. La temática naturalista, que maneja con suma seguridad y éxito en $S i n$ rumbo, no bastaría para darle su renombre, si no fuera también por la economía y el arte de su estructura. La novela posee una concentración narrativa admirable que merece el término de clásico. Y este supremo arte de novelar no se verá igualado ni superado en la novelística hispanoamericana hasta treinta años después, ya en el siglo XX, con Los de abajo. 


\section{NOTAS}

1. Martín García Mérou, contemporáneo de Cambaceres, que incluyó en su obra critica Libros y autores (Buenos Aires: Félix Lajouane, 1886) un ensayo sobre "Las novelas de Cambaceres", pp. 71-90, hecho con inteligencia y simpatìa.

2. Sin rumbo (New York: Anaya Book Co., 1971), pp. 7-29. Véase también Cedomil Goić, Historia de la novela hispanoamericana (Valparaiso: Ediciones Universitarias de Valparaǐso, 1972), pp. 118-120; y R. Anthony Castagnaro, The Early Spanish American Novel (New York: Las Americas Publishing Co., 1971), pp. 119-129.

3. Eugenio Cambaceres, Sin rumbo (Buenos Aires: Editorial Huemul, 1966), con Introducción, notas y vocabulario de Isabel Santacatalina, p. 25. Todas las citas están tomadas de esta edición y de aquỉ en adelante aparecerán en el texto con la página señalada.

4. El motivo de la oveja sangrienta se repite también en el penúltimo capitulo cuando la hija de Andrés, operada por el médico, le hacia a su padre "el efecto de un cordero degollado" (p. 161).

5. Bastos, op. cit., mantiene que el punto central de la novela siempre presente es "el tedio de Andrés-los incidentes le dan relieve, lo matizan" (p. 19).

6. El putrilago social (p. 101); piel pustulosa (p. 109); eretismo nervioso (p. 145); vomitivo de hemético (p. 148); febriciente (p. 100, p. 123, p. 150); la pieza del hotel roñosa y pulguienta (p. 105), etc.

7. Este motivo de la venganza aparece frustrada en el capitulo XI que describe la yerra y aparta del ganado de una manera costumbrista reminiscente al capítulo inicial de la esquila. Se repite la violencia del primer episodio, pero ahora no es el patrón que ataca sino el Chino Contreras. Esta trata de asesinar a Andrés soltándole un toro.

8. Bastos, p. 20. 1963), pp. 24-25.

9. Edwin Muir, Structure of the Novel (London: The Hogarth Press,

10. Unos ejemplos de novelistas aficionados al recurso son Rómulo Gallegos (Doña Bárbara y Santos Luzardo), Eduardo Mallea (Agata Cruz en Todo verdor perecerá), etc.

11. Bastos, p. 21. 
